\title{
Characteristic bending strength of beech glulam
}

\author{
M. Frese* and H.J. Blaß \\ *Lehrstuhl für Ingenieurholzbau und Baukonstruktionen \\ University of Karlsruhe \\ 76128 Karlsruhe, Germany \\ Fax 07216084081 \\ matthias.frese@holz.uka.de \\ Tel +497216087948
}

\begin{abstract}
This project was carried out to derive the characteristic bending strength of beech glulam. 47 full size glulam beams with combined symmetrical lay-up were produced. For this purpose mechanical grading was used to classify the lamellae according to the dynamic MOE. The beams were tested according to EN 408. The bending strength exceeds $44,5 \mathrm{~N} / \mathrm{mm}^{2}$. The structural properties of beech boards were determined as input for a finite-element-based computer model. It was specifically developed to predict the bending strength of beech glulam. Comparisons between the experimental data and the analytical results from the computer model show a good agreement. Depending on the bending strength of finger joints and the tensile strength of boards design proposals were numerically derived taking into account visual and/or mechanical grading.
\end{abstract}

\section{Résumé}

L'article présente une méthode de calcul pour la résistance à la flexion du bois lamellé collé en hêtre. On a produit 47 poutres expérimentales qui avaient la dimension d'éléments de construction et une structure symmétrique et combinée. On a classé les planches de bois suivant leur résistance en déterminant leur rigidité axiale. Les poutres ont été testées en flexion à quatre points selon l'EN 408. Les résultats montrent une résistance à la flexion de plus de $44,5 \mathrm{~N} / \mathrm{mm}^{2}$. Les propriétés structurelles d'une quantité de planches de bois de hêtre ont été déterminées. Ces données sont utilisées dans un modèle de calcul qui se base sur la méthode des éléments finis. Ce modèle permet de prédire la résistance à la flexion des poutres en bois lamellé collé en hêtre. Un bon accord a été observé entre les résultats expérimentaux et les résultats théoriques. Avec le modèle de calcul on donne quelques propositions pour la détermination des valeurs caractéristiques qui prennent pour base la résistance à la flexion d'aboutages à entures et la résistance à la traction de planches. Dans ces propositions on tient compte du classement visuel ou/et mécanique des bois suivant leur résistance.

\section{Introduction}

The bending strength of glulam depends on the tensile strength of the lamellae and of the finger joints which may correlate. If the correlation is known, it is possible to determine the characteristic bending strength of glulam depending only on the characteristic tensile strength of the lamellae. In the case of softwood this leads to the calculation model in EN 1194, where a linear relation between the two values is given. The bending strength of the glulam and the tensile strength of the lamellae are determined based on test methods defined in EN 408. The results of these test methods lead to the so called laminating effect. This means, that the bending strength of glulam is generally higher than the tensile strength of the lamellae. The high tensile strength of beech (fagus silvatica) raises the question, whether the common 
relation according to EN 1194 is also valid for a characteristic tensile strength exceeding 26 $\mathrm{N} / \mathrm{mm}^{2}$ or if a different relation more accurately describes the laminating effect for beech glulam. The aim of the present study is to answer this question and to provide design models for beech glulam. An overview of the conducted work and research is given below: Regression equations were derived to predict the mechanical properties of $150 \mathrm{~mm}$ long board sections and $150 \mathrm{~mm}$ long finger joints. The structural properties of 1888 beech lamellae graded according to the dynamic $\mathrm{MOE}$ from longitudinal vibration $\left(=\mathrm{E}_{\mathrm{dyn}}\right)$ are described. A new calculation model consisting of a simulation programme and a finite element programme was developed. This model is appropriate to numerically reproduce 4 point bending tests according to EN 408. Full size beams with combined lay-up having mechanical properties of beech glulam can be analysed. In an experimental investigation 4 point bending tests on full size beech glulam incorporating the 1888 boards were carried out. A comparison between the results from the bending tests and the numerical results is given to verify the calculation model. 4 point bending tests on finger joints taking into account visual and mechanical grading were conducted. The results clarify the influence of the grading method on the strength of finger joints. Different visual and mechanical grading procedures partly suitable for practical application were developed for use in the calculation model. The required input data were generated by computer-aided grading using the database of the 1888 boards. The numerical determination of bending strength of $600 \mathrm{~mm}$ high beams considering the grading proposals provides a database making it possible to describe the laminating effect and to work out a design model for beech glulam.

\section{Modelling lamellae}

The bending strength and the MOE of a glulam beam modelled in the simulation programme is mainly affected by the ratios of values tensile strength $\left(=f_{t}\right) / \operatorname{MOE}\left(=E_{t}\right)$ and compression strength $\left(=f_{c}\right) / \operatorname{MOE}\left(=E_{c}\right)$. These values vary in longitudinal direction of the lamellae. The following empirical equations were developed to determine the mechanical properties (in $\mathrm{N} / \mathrm{mm}^{2}$ ) of lamellae discretised in $150 \mathrm{~mm}$ steps. In the following equations, an additional index $\mathrm{j}$ denotes finger joints. The extensive database describing the tension and compression tests on $150 \mathrm{~mm}$ board sections and finger joints was provided by Glos et al. [2]. More background information concerning the property variation and the effects of autocorrelation can be found in [3] and general concepts of simulating glulam beams in [4].

\subsection{Mechanical properties of board sections}

The regression equations (1) to (4) predict the mechanical properties of $150 \mathrm{~mm}$ long board sections. The MOE is closely correlated with the strength. Hence the MOE is modelled first and appears as independent variable when modelling the strength values. The DEB-value $(0,05-0,85)$ is a knot ratio quantifying single knots in accordance with DIN 4074. $\rho_{0}(575-820$ $\left.\mathrm{kg} / \mathrm{m}^{3}\right)$ is the oven-dry density of beech and $\mathrm{u}(+/-12 \%)$ is the moisture content.

$$
\begin{aligned}
& \ln \left(E_{c}\right)=-3,46+3,91 \cdot 10^{-2} \cdot \rho_{0}-7,44 \cdot 10^{-2} \cdot u-1,92 \cdot D E B-2,75 \cdot 10^{-5} \cdot \rho_{0}^{2} \\
& \ln \left(f_{c}\right)=2,88+1,13 \cdot 10^{-4} \cdot E_{c}-2,71 \cdot 10^{-9} \cdot E_{c}^{2} \\
& \ln \left(E_{t}\right)=3,36 \cdot 10^{-1}+2,64 \cdot 10^{-2} \cdot \rho_{0}-1,56 \cdot D E B-1,87 \cdot 10^{-5} \cdot \rho_{0}^{2} \\
& \ln \left(f_{t}\right)=3,09+9,76 \cdot 10^{-5} \cdot E_{t}-1,54 \cdot 10^{-4} \cdot E_{t} \cdot D E B
\end{aligned}
$$




\subsection{Mechanical properties of finger joints}

The regression equations (5) and (6) predict the mechanical properties of finger joints in the compression zone of the beam. Aicher et al. [5] carried out tensile tests on finger joints. They found a correlation with $\mathrm{r}^{2}=0,45$ between the tensile strength and the lower longitudinal MOE of the connected boards. The MOE of both boards was measured in the range $350 \mathrm{~mm}$ in length. The distance between the finger joint and the beginning of the range was $58 \mathrm{~mm}$. The correlation indicates the use of the minimum dynamic MOE $=E_{\text {dyn,min }}$ (9700-20600 $\mathrm{N} / \mathrm{mm}^{2}$ ) as independent variable when predicting the mechanical properties in the tensile zone of the beam. The equations (7) and (8) are used when modelling mechanical grading by measuring the dynamic MOE. In this case the MOE difference between the connected boards is small. Visual grading does not consider the MOE as grading parameter of the boards. Hence connections between boards with a low and high MOE are possible. For this case the equations (9) and (10) applies. $\rho_{0, \min }$ and $\rho_{0, \max }\left(\mathrm{kg} / \mathrm{m}^{3}\right)$ indicate the smallest and highest density, respectively, of the joined boards.

$$
\begin{aligned}
& E_{c, j}=1,01 \cdot 10^{5}-1,55 \cdot 10^{4} \cdot u+6,44 \cdot 10^{2} \cdot u^{2}+9,57 \cdot 10^{-3} \cdot \rho_{0, \max }{ }^{2} \\
& f_{c, j}=-2,10 \cdot 10^{2}+40,4 \cdot u-1,74 \cdot u^{2}+2,73 \cdot 10^{-6} \cdot E_{c, j} \cdot \rho_{0, \text { min }} \\
& E_{t, j}=3,20 \cdot 10^{3}+0,823 \cdot E_{d y n, \text { min }} \\
& f_{t, j}=63,2-8,27 \cdot 10^{-5} \cdot \rho_{0, \text { min }}{ }^{2}+1,82 \cdot 10^{-7} \cdot E_{d y n, \text { min }} \cdot E_{t, j} \\
& E_{t, j}=7,67 \cdot 10^{3}+0,538 \cdot E_{d y n, \text { min }} \\
& f_{t, j}=54,5-5,04 \cdot 10^{-5} \cdot \rho_{0, \text { min }}{ }^{2}+1,60 \cdot 10^{-7} \cdot E_{d y n, \text { min }} \cdot E_{t, j}
\end{aligned}
$$

\subsection{Structural properties of beech}

\subsubsection{Material, methods and results}

The mechanical properties calculated from the equations (1) to (10) depend on the structural properties density, knot ratio and moisture content. 1888 boards were examined to determine these properties. Three sawmills located in Germany each delivered about one third of the testing material, see Table 1 . The gross density (= air dry mass/volume) and the dynamic MOE as grading parameter of each board were measured. The measurement is described in [1]. The boards were graded according to the system shown in Table 2. Fig. 1 depicts the yield. About one third of the boards is in the highest grades 4 and 5. This allowed a combined lay-up with lamellae of high stiffness in the outer zone of the test beams.

Table 1 Sample size and cross-sectional dimensions ( $\mathrm{mm})$

\begin{tabular}{|c|c|c|}
\hline source & sample size & height / width $(\mathrm{mm})$ \\
\hline Spessart & 670 & $41 / 121$ \\
Nordhessen & 659 & $40 / 116$ \\
Schönbuch & 559 & $44 / 115$ \\
\hline
\end{tabular}


Table 2 Mechanical grading according to dynamic MOE

\begin{tabular}{|c|c|}
\hline grade & range of dynamic $\mathrm{MOE}\left(\mathrm{N} / \mathrm{mm}^{2}\right)$ \\
\hline 1 & $\mathrm{E}_{\text {dyn }} \leq 13000$ \\
2 & $13000<\mathrm{E}_{\text {dyn }} \leq 14000$ \\
3 & $14000<\mathrm{E}_{\text {dyn }} \leq 15000$ \\
4 & $15000<\mathrm{E}_{\text {dyn }} \leq 16000$ \\
5 & $16000<\mathrm{E}_{\text {dyn }}$ \\
\hline
\end{tabular}

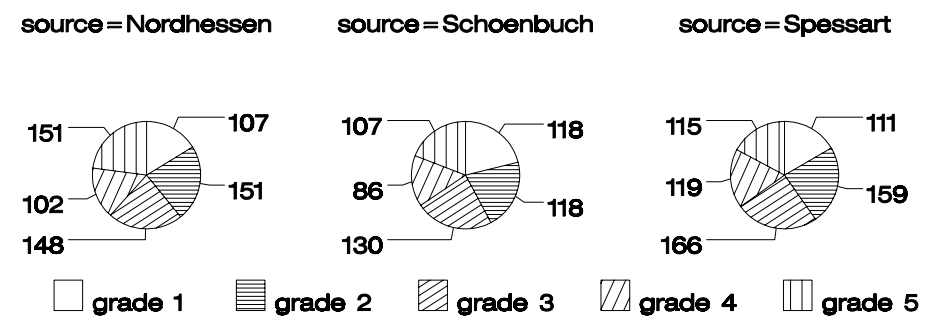

Fig. 1 Absolute yield in the 5 grades

The knots were determined according to DIN 4074 considering only the single knot with the DEB-value. All the knots appearing in the boards were taken into account in order to reproducing their appearance while simulating the lamellae. A typical feature of beech is the high amount of boards being free from knots, see Fig. 2.

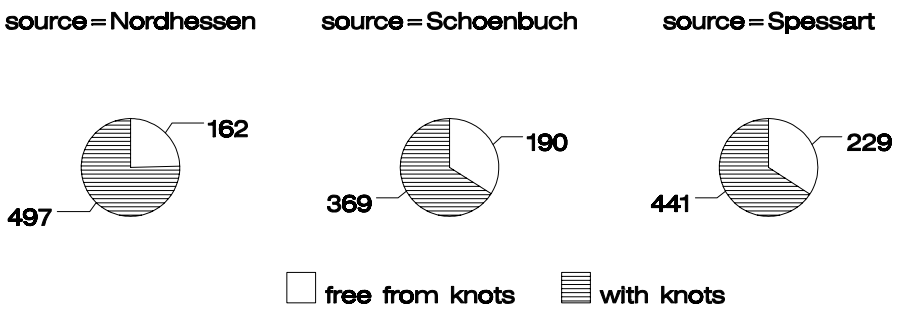

Fig. 2 Fraction of boards being free from knots

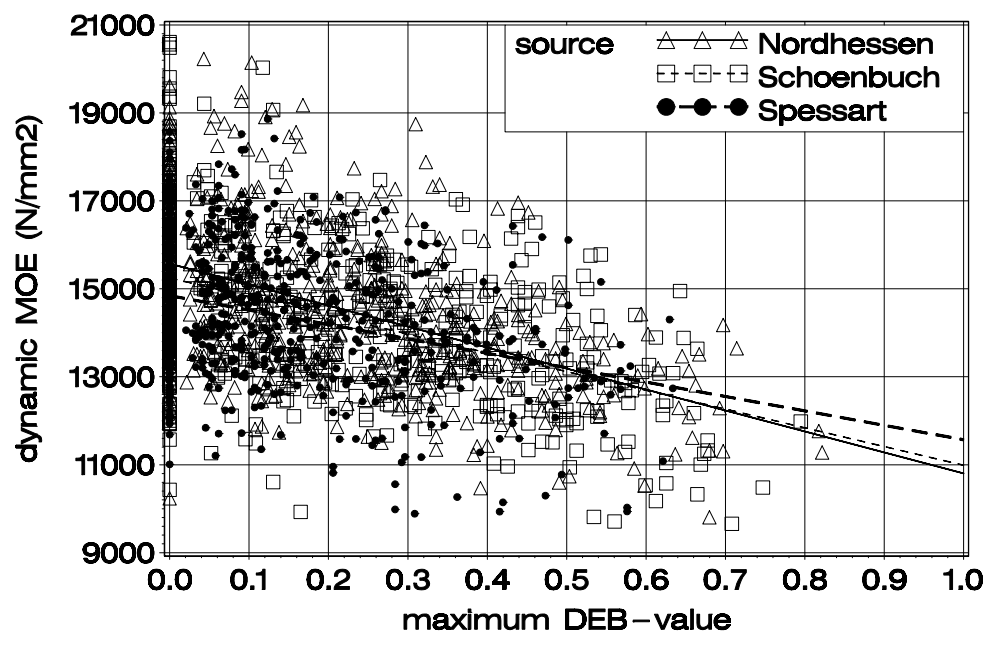

Fig. 3 Dynamic MOE depending on maximum DEB-value 
Fig. 3 shows the relation between the dynamic MOE and the maximum DEB-value. It is evident, that the dynamic MOE decreases with increasing maximum DEB-value. The trend is independent of the source of the boards. The linear relation is superposed by a strong residual scattering. Hence the following proposals for mechanical grading in section 7.1 additionally consider the maximum DEB-value as a second grading parameter.

The moisture content of the boards is given in Table 3 .

Table 3 Moisture content statistics (\%)

\begin{tabular}{|c|c|c|c|}
\hline source & mean & std deviation & range \\
\hline Spessart & 11,3 & 0,595 & $8,15-13,4$ \\
Nordhessen & 9,95 & 0,538 & $8,85-11,9$ \\
Schönbuch & 10,5 & 0,597 & $9,14-11,7$ \\
\hline
\end{tabular}

\subsubsection{Density functions of the structural properties}

The simulation of the structural properties of the lamellae is based on random number generation taken from density functions. These were fitted to the empirical data. The fit was carried out for each of the grades in Table 2 and each structural property. The advantage of this approach is a very exact simulation of the structural properties within a grade. The lognormal and beta density function are suitable to describe the structural properties. Table 4 provides the gross density statistics for each grade. The grading influence on the statistics and on the shape of the density functions is evident. Fig. 4 exemplifies this for grades 1, 3 and 5.

Table 4 Gross density statistics $\left(\mathrm{kg} / \mathrm{m}^{3}\right)$

\begin{tabular}{|c|c|c|c|}
\hline grade & $\mathrm{n}$ & mean & std deviation \\
\hline 1 & 336 & 657 & 32,5 \\
2 & 428 & 662 & 30,9 \\
3 & 444 & 674 & 28,6 \\
4 & 307 & 685 & 27,0 \\
5 & 373 & 706 & 30,2 \\
\hline
\end{tabular}

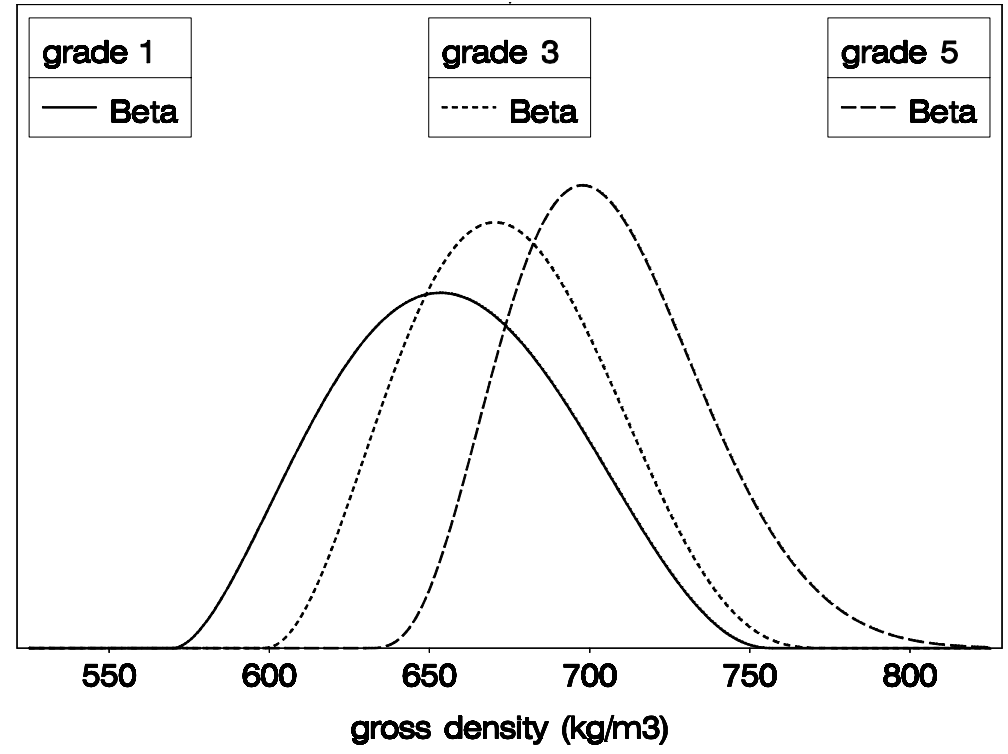

Fig. 4 Fitted beta density for gross density 
The relation between the oven-dry density $\left(\right.$ in $\left.\mathrm{kg} / \mathrm{m}^{3}\right)$ of beech and the gross density $\left(=\rho_{\text {gross }}\right.$ in $\mathrm{kg} / \mathrm{m}^{3}$ ) at about $10 \%$ moisture content is given by equation (11).

$$
\rho_{0}=22,7+0,952 \cdot \rho_{\text {gross }}
$$

Table 5 shows the maximum DEB-value statistics. Only boards with knots were taken into account. It is evident that grading according to the dynamic MOE is also an efficient method to detect knots. The fraction of boards with knots decreases with higher grades. Mean and std deviation show a similar trend. There are as shown in Fig. 5 significant differences between the shape of the fitted beta density functions. Further DEB-values being smaller than the maximum DEB-value appearing along the board are simulated following the method developed by Görlacher [1]. In the current case of beech the method additionally takes into account the number of sections with knots. The statistics of this feature shows Table 6. Fig. 6 displays the moderate influence of the grading technique according to Table 2 on the number of sections with knots. The fitted density curves are quite similar.

Table 5 Maximum DEB-value statistics

\begin{tabular}{|c|c|c|c|c|}
\hline grade & n (with knots) & fraction & mean & std deviation \\
\hline 1 & 289 & 0,86 & 0,358 & 0,183 \\
2 & 316 & 0,74 & 0,261 & 0,164 \\
3 & 295 & 0,66 & 0,222 & 0,141 \\
4 & 200 & 0,65 & 0,183 & 0,119 \\
5 & 207 & 0,55 & 0,153 & 0,110 \\
\hline
\end{tabular}

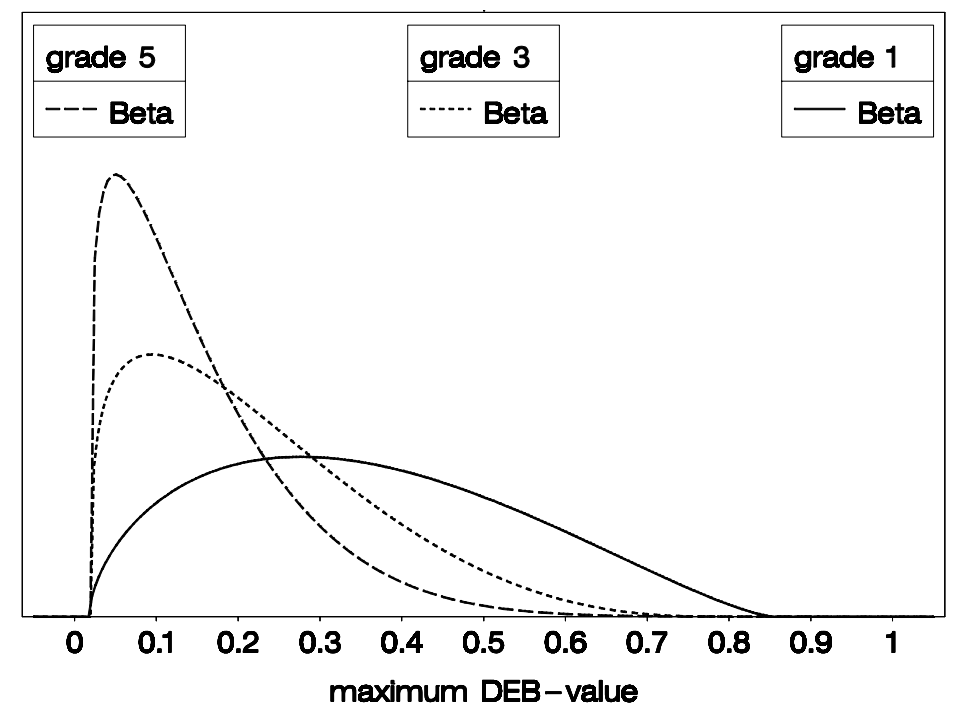

Fig. 5 Fitted beta density for maximum DEB-value

Table $6 \quad$ Number of sections with knots statistics

\begin{tabular}{|c|c|c|c|}
\hline grade & n (with knots) & mean & std deviation \\
\hline 1 & 289 & 2,85 & 1,92 \\
2 & 316 & 2,77 & 1,81 \\
3 & 295 & 2,43 & 1,56 \\
4 & 200 & 2,55 & 1,67 \\
5 & 207 & 2,24 & 1,50 \\
\hline
\end{tabular}




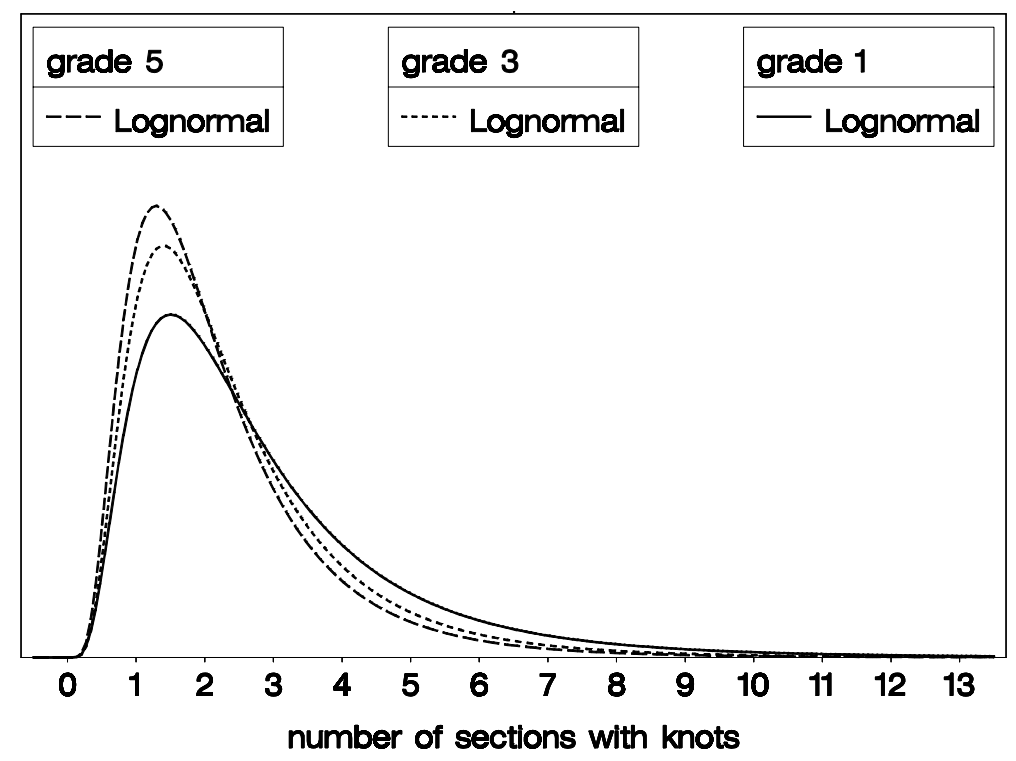

Fig. 6 Fitted lognormal density for number of sections with knots

The histogram and fitted lognormal density for the board length is shown in Fig. 7. The distribution of the empirical data is irregular. This is caused by the different length of the basic material. The original board length is chiefly $3 \mathrm{~m}$ and the rest $4 \mathrm{~m}$ and $5 \mathrm{~m}$. The required preparation of the board ends with regard to finger jointing causes a reduction up to 1,5 $\mathrm{m}$. Hence a maximum range of about $3,2 \mathrm{~m}$ can be observed.

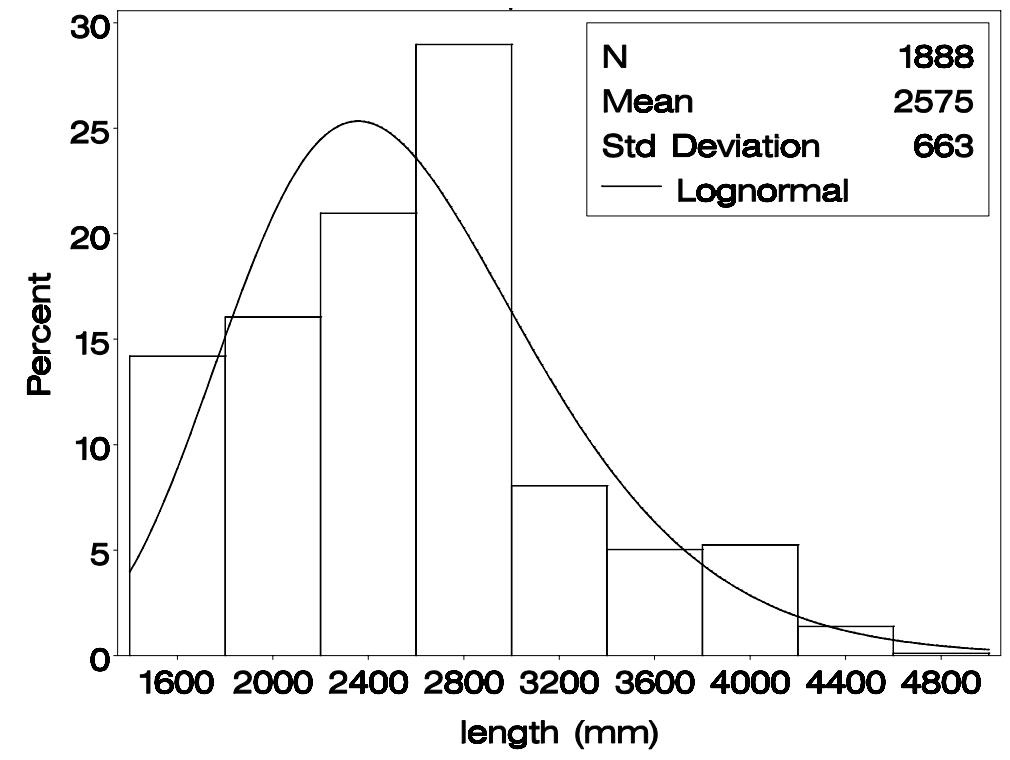

Fig. 7 Histogram and fitted lognormal density of the board length 


\section{Calculation model}

\subsection{Simulation programme}

The simulation programme is comparable to the real glulam production. A continuous lamella is generated consisting of simulated boards and finger joints. The mechanical properties are determined in steps $150 \mathrm{~mm}$ in length. Considering that each board is an individual item, the structural properties and their variation are determined individually for each board. Here, the effect of autocorrelation is taken into account. The result are boards of low up to high quality. The activation of different density functions enables the simulation of a grading process according to the method in Table 2 as well as the grading proposals in Table 13 with regard to practical application. In general beams with combined lay-ups are simulated taking into account the economical use of the higher grade boards (Fig. 8). There is as a minimum 2 lamellae in the outer zone.

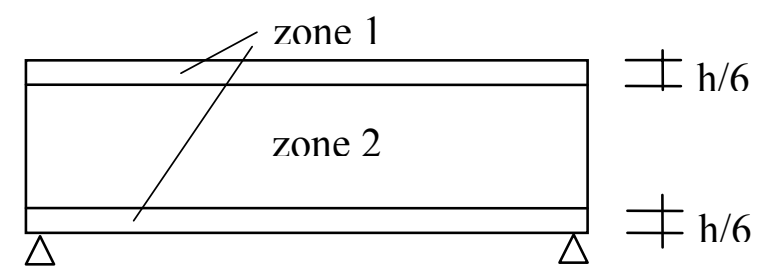

Fig. 8 Lay-up of a combined glulam beam

The dynamic MOE is a dependent variable and the leading mechanically determined grading parameter. In the simulation programme he is calculated from the stiffness properties of a simulated board with formula (12): the common rule of serial connection of springs having different stiffness. The factor of 1,05 considers the influence of the dynamic testing method. $E_{\text {stat }}$ is the mean MOE in terms of static load. $E_{i}$ quantifies the variable MOE of a single section and $\mathrm{i}$ is the number of sections along the discretised lamella. If the value of the dynamic MOE - calculated in a loop - is within the limits of the desired grade, the board is included in the simulated beam. All the mechanical properties are stored in a two-dimensional array for later use in the finite element programme. Additionally, the simulation programme can provide for a characteristic tensile strength of finger joints.

$$
\mathrm{E}_{\mathrm{dyn}} \approx 1,05 \cdot \mathrm{E}_{\text {stat }}=1,05 \cdot \frac{\mathrm{N}}{\sum_{\mathrm{i}=1}^{\mathrm{N}} \frac{1}{\mathrm{E}_{\mathrm{i}}}}
$$

\subsection{Finite element programme}

The beam bending strength and MOE are calculated using the finite element programme ANSYS Version 5.7. Fig. 9 shows the mechanical model. Instead of a load a stepwise displacement $\Delta \mathrm{u}$ is applied in the middle of the loading equipment. The load in the vertical compression members $(\mathrm{F})$ is stored after each step for later determination of the maximum load $\left(F_{\max }\right)$. The bending strength $\left(f_{m}\right)$ is calculated using formula (13) with the section modulus $(\mathrm{W})$.

$$
\mathrm{f}_{\mathrm{m}}=\frac{\mathrm{F}_{\max } \cdot \ell / 3}{\mathrm{~W}}
$$




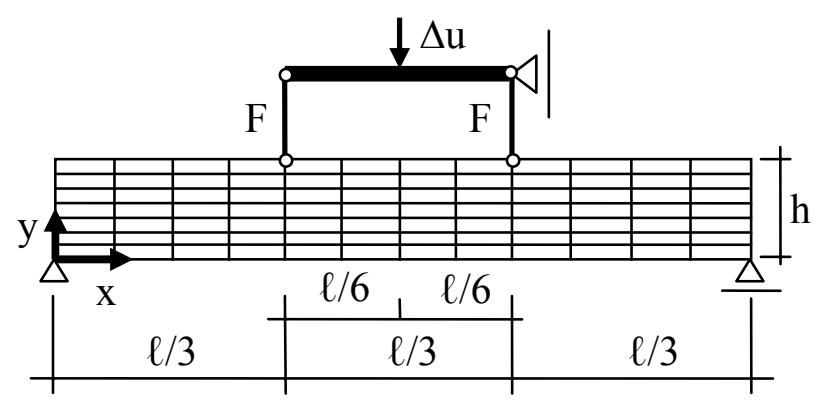

Fig. 9 Finite element model

The material is orthotropic. In the compressive zone ideal elastoplasticity and in the tensile zone ideal elasticity until failure is assumed. A failure in the outermost lamination generally stops the calculation. Failure occur if the tension stress in the centre of an element lies in between a range $+/-0,5 \%$ of the tensile strength of the board section. Element failure in the tensile zone outside the outermost lamination do not constitute beam failure and hence is allowed during the calculation. Those elements were deactivated during the calculation by multiplying their stiffness by a severe reduction factor.

\section{Bending tests on beech glulam beams}

47 test beams were produced and tested according to EN 408. Differing from Table 2 the boards coming from Nordhessen and Schönbuch were graded in up to 7 grades, see Table 7. The range of variation concerning the MOE of the outer laminations of the combined test beams was increased. Hence 2 test beams were produced with lamellae in zone 1 belonging to grade 7 . The beams are divided into 5 series differing in terms of beam height and grade of lamellae.

Table 7 Subdivision of grade 5 boards coming from Nordhessen and Schönbuch

\begin{tabular}{|c|c|}
\hline Grade & range of dynamic MOE $\left(\mathrm{N} / \mathrm{mm}^{2}\right)$ \\
\hline $5 \rightarrow\left\{\begin{array}{l}5^{*} \\
6 \\
7\end{array}\right.$ & $16000<\mathrm{E}_{\mathrm{dyn}} \leq 17000$ \\
& $17000<\mathrm{E}_{\mathrm{dyn}} \leq 18000$ \\
\end{tabular}

\subsection{Beam lay-up}

3 strength classes and 2 beam heights were realised, see Table 8 . Fig. 8 and Table 9 give details of the beam lay-up. The total amount of 1888 boards was used to produce the beams. This confirms the economical aspect of the proposed grading system in Table 2.

Table 8 Acronym for strength class of the 5 series

\begin{tabular}{|c|c|c|}
\hline height $\mathrm{h}(\mathrm{mm})$ & 340 & 600 \\
\cline { 1 - 1 } strength class & & VH-60 \\
very high & VH-34 & H-60 \\
high & H-34 & - \\
low & L-34 & Nordhessen Schönbuch \\
source & Spessart & 9,00 \\
span $\ell(\mathrm{m})$ & 5,10 & \\
\hline
\end{tabular}


Table 9 Strength class and combined beam lay-up

\begin{tabular}{|c|c|c|}
\hline strength class & grade of boards in zone 1 & grade of boards in zone 2 \\
\hline very high & 5 & 3 \\
high & 4 & 2 \\
low & 1 & 1 \\
\hline
\end{tabular}

\subsection{Results}

Fig. 10 shows the relation between bending strength and MOE. The statistics of these values are given in Table 10. The following conclusions can be drawn:

- The grade of the lamellae obviously affects the bending strength and the MOE of the tested beams.

- The strength depends on the height.

- The strength values belonging to the strength classes "high" and "very high" exceed the lower limit of $44,5 \mathrm{~N} / \mathrm{mm}^{2}$. The $5^{\text {th }}$ percentile strength value of beech glulam manufactured from mechanically graded boards is in the order of this value.

Table 10 Bending strength and MOE statistics

\begin{tabular}{|c|c|c|c|c|}
\hline & & height h (mm) & 340 & 600 \\
\hline \multirow{3}{*}{ 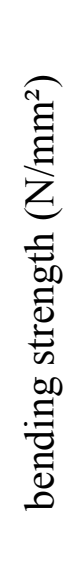 } & very high & $\begin{array}{c}\mathrm{n} \\
\text { mean } \\
\text { std dev. } \\
\text { min }\end{array}$ & $\begin{array}{l}11 * \\
63,7 \\
7,51 \\
50,4\end{array}$ & $\begin{array}{c}10 \\
55,9 \\
5,78 \\
46,9\end{array}$ \\
\hline & high & $\begin{array}{c}\mathrm{n} \\
\text { mean } \\
\text { std dev. } \\
\text { min }\end{array}$ & $\begin{array}{c}12 \\
57,8 \\
9,32 \\
46,6\end{array}$ & $\begin{array}{c}8 \\
50,5 \\
5,21 \\
44,5\end{array}$ \\
\hline & low & $\begin{array}{c}\mathrm{n} \\
\text { mean } \\
\text { std dev. } \\
\text { min }\end{array}$ & $\begin{array}{c}5 \\
43,3 \\
7,25 \\
35,0\end{array}$ & $\begin{array}{l}- \\
- \\
-\end{array}$ \\
\hline \multirow{3}{*}{ 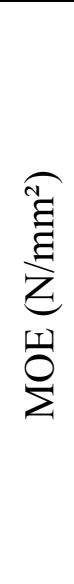 } & very high & $\begin{array}{c}\mathrm{n} \\
\text { mean } \\
\text { std dev. } \\
\text { min }\end{array}$ & $\begin{array}{c}12 \\
15500 \\
490 \\
14700\end{array}$ & $\begin{array}{c}10 \\
16000 \\
799 \\
15100\end{array}$ \\
\hline & high & $\begin{array}{c}\mathrm{n} \\
\text { mean } \\
\text { std dev. } \\
\text { min }\end{array}$ & $\begin{array}{c}12 \\
14400 \\
383 \\
13700\end{array}$ & $\begin{array}{c}8 \\
14400 \\
265 \\
14000\end{array}$ \\
\hline & low & $\begin{array}{c}\mathrm{n} \\
\text { mean } \\
\text { std dev. } \\
\text { min }\end{array}$ & $\begin{array}{c}5 \\
12300 \\
403 \\
11800\end{array}$ & $\begin{array}{l}- \\
- \\
-\end{array}$ \\
\hline
\end{tabular}




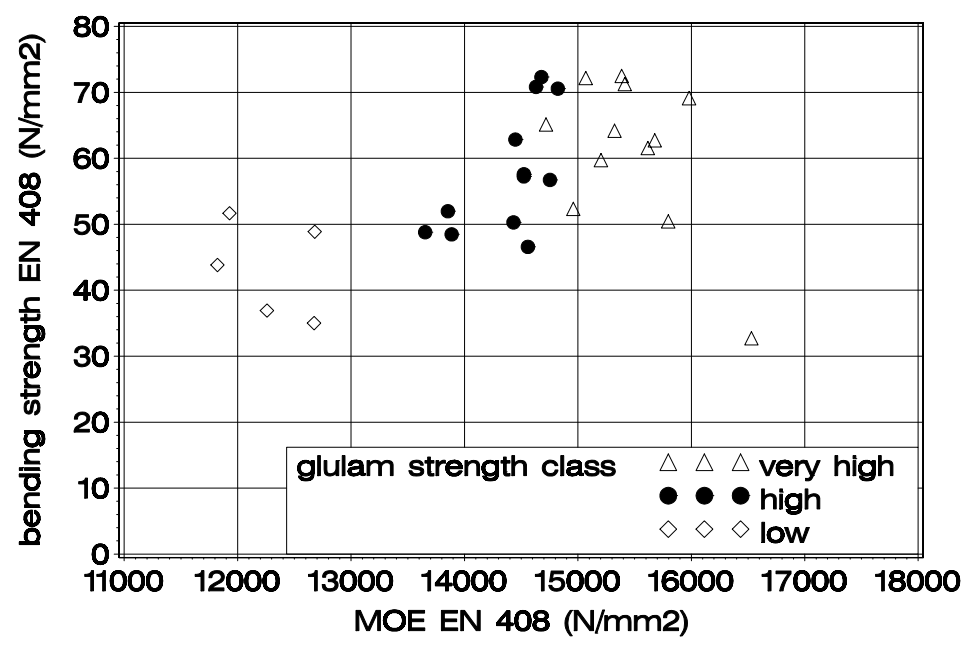

Fig. 10 Bending strength depending on MOE; beam height $\mathrm{h}=34 \mathrm{~cm}$

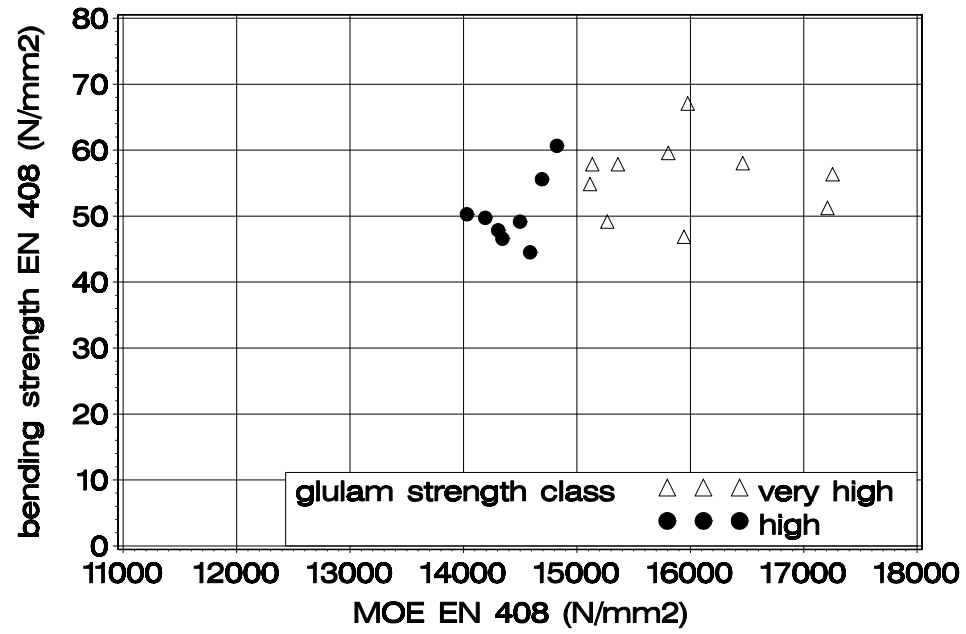

Fig. 10 (Continuation) Bending strength depending on MOE; beam height $\mathrm{h}=60 \mathrm{~cm}$

\section{Bending strength of finger joints}

108 bending tests on finger joints manufactured from visually graded boards were performed, see Table 11. A further 259 tests were carried out to study the influence of mechanical grading on the bending strength of finger joints, see Table 12. These specimens were manufactured in the laboratory from the undamaged parts of tested beams. It was possible to assign the specimens to the grades and to the source of the connected boards. All the bending tests were conducted flatways according to EN 408 with a span of 15 times the height. The flexural MOE obtained by vibration methods is the reference parameter, see Fig. 11 and [6].

Table 11 Sample size and cross-sectional dimensions

\begin{tabular}{|c|c|c|c|}
\hline source & Spessart & Nordhessen & Schönbuch \\
\hline $\mathrm{N}$ & 31 & 56 & 21 \\
\hline width/height $(\mathrm{mm})$ & $110 / 34$ & $100 / 30$ & $105 / 36$ \\
\hline
\end{tabular}


Table 12 Sample size and cross-sectional dimensions

\begin{tabular}{|c|c|c|c|}
\hline $\begin{array}{c}\text { source } \\
\text { grade }\end{array}$ & Spessart & Nordhessen & Schönbuch \\
\hline 2 & 21 & 20 & 22 \\
3 & 25 & 22 & 22 \\
4 & 18 & 22 & 22 \\
5 & $\underline{24}$ & $\underline{19}$ & $\underline{22}$ \\
$\Sigma$ & 88 & $100 / 29$ & $105 / 34$ \\
\hline width/height $(\mathrm{mm})$ & $110 / 33$ & & \\
\hline
\end{tabular}

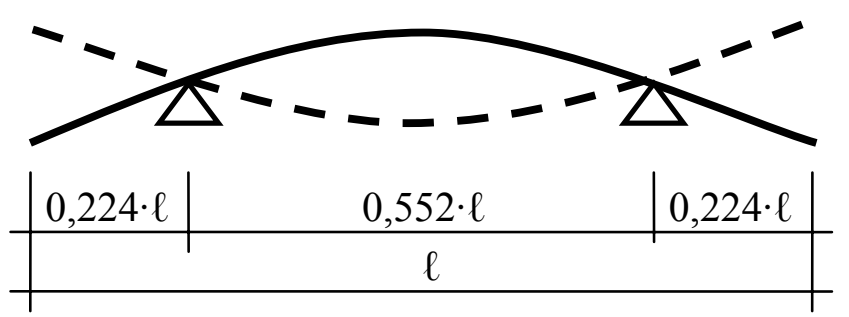

Fig. 11 Flatways flexural vibration; the finger joint connection is in the middle of the specimen and $\ell$ is the specimen length

\subsection{Visual grading of boards}

The relation between bending strength and flexural MOE is shown in Fig. 12. The 3 regression lines confirm the influence of stiffness on the bending strength. The $5^{\text {th }}$ percentile is $56 \mathrm{~N} / \mathrm{mm}^{2}$ in case of visual grading.

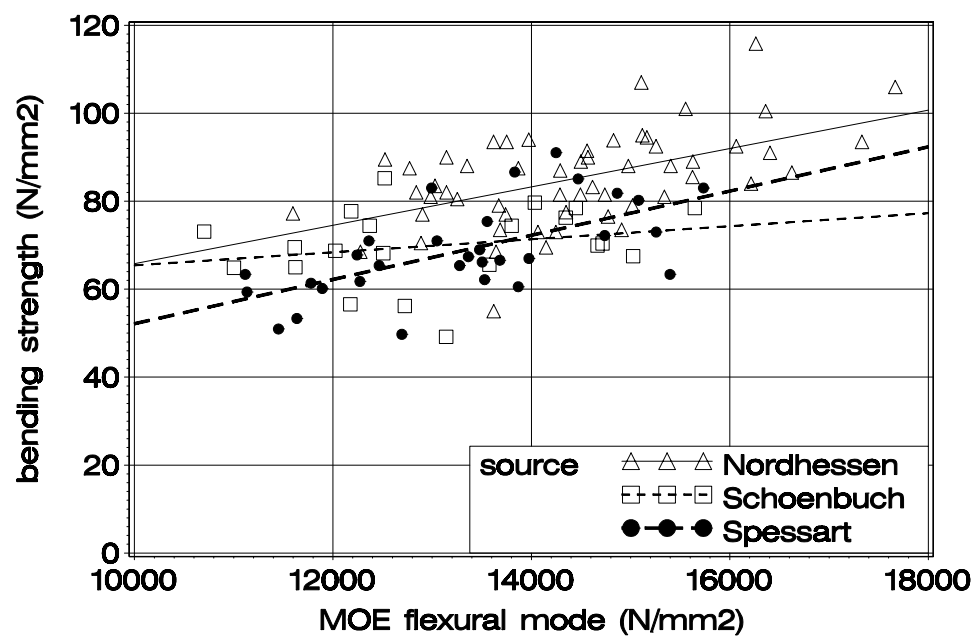

Fig. 12 Bending strength depending on flexural MOE

\subsection{Mechanical grading of boards}

Fig. 13 shows the relation between bending strength and flexural MOE and Fig. 14 the mean and $5^{\text {th }}$ percentile value of bending strength comparing the different grades. It is remarkable, 
that no increase of bending strength between grades 4 and 5 can be proved. The $5^{\text {th }}$ percentile value of the 127 specimens belonging to grades 4 and 5 both amount to $68,8 \mathrm{~N} / \mathrm{mm}^{2}$. In terms of technical feasibility mechanical grading of grades 4 and 5 can lead to a $5^{\text {th }}$ percentile value exceeding $70 \mathrm{~N} / \mathrm{mm}^{2}$.

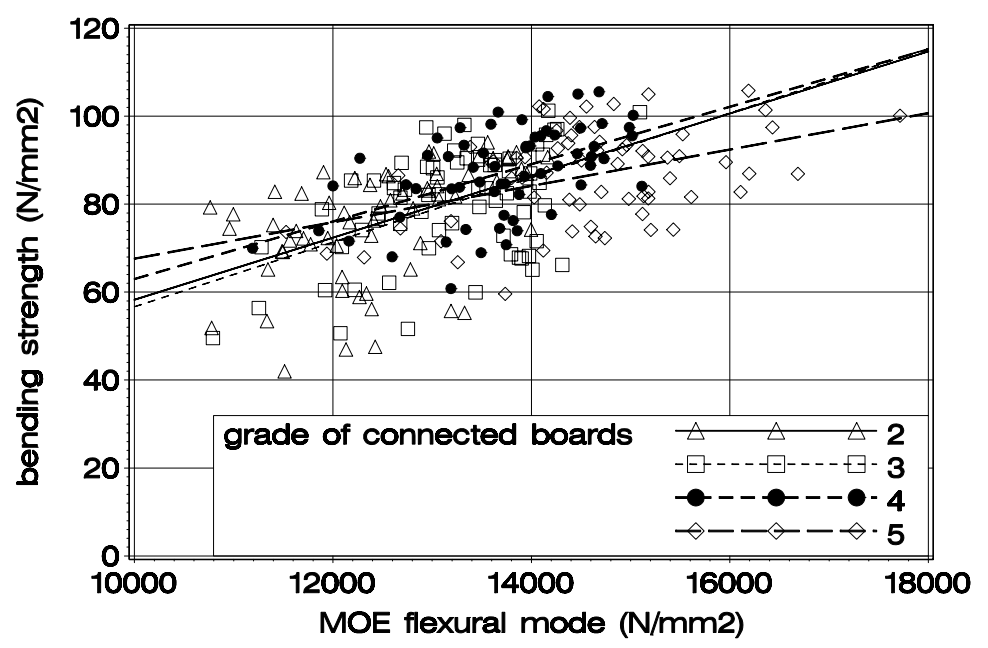

Fig. 13 Bending strength depending on flexural MOE

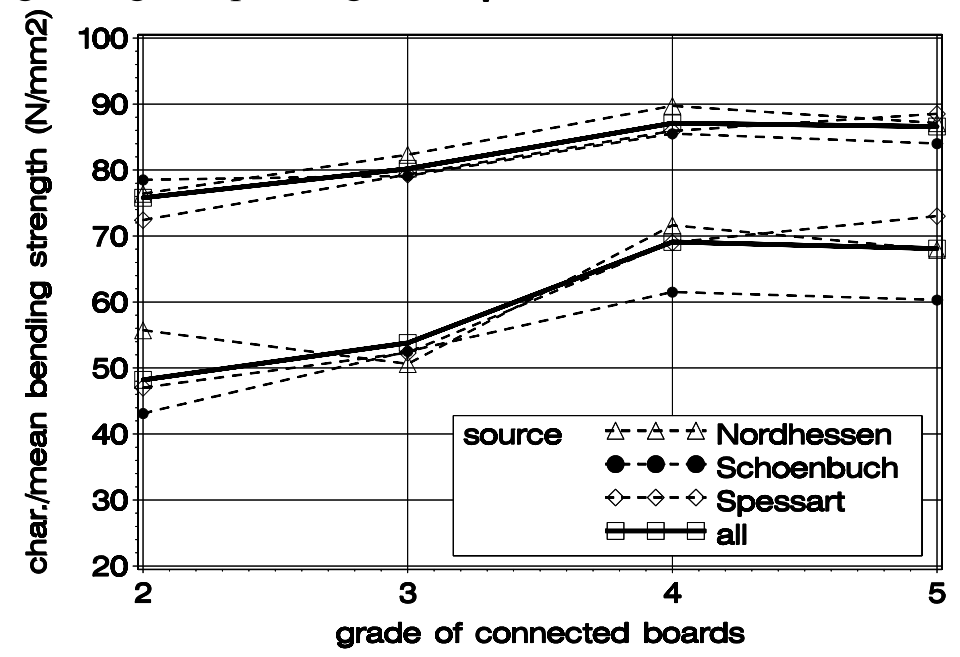

Fig. 14 Mean (top) and $5^{\text {th }}$ percentile (bottom) bending strength value over grade of connected boards

\section{Verifying the calculation model}

The beams of the 5 series were modelled with the calculation model taking into account the lay-up and the distribution of the structural properties of the laminated boards. 500 simulations were conducted per series. The $5^{\text {th }}$ percentile value of the tensile strength of finger joints was predicted using equation (8). The values are $53 \mathrm{~N} / \mathrm{mm}^{2}$ (grade 5 ), $48 \mathrm{~N} / \mathrm{mm}^{2}$ (grade 4) and $36 \mathrm{~N} / \mathrm{mm}^{2}$ (grade 1). The moderate increase of tensile strength of 53/48 =1,10 between grades 4 with 5 is not confirmed by the bending tests on finger joints. Considering the small sample size of test specimens in grades 4 and 5 it is still plausible to assume higher values in grade 5. Fig. 15 compares the test results and the simulations. The test results are situated 
mainly in the range mean value $+/-$ std deviation of the simulation. The dependence of the strength on the height and the influence of board grade on the bending strength is reproduced correctly. Hence the calculation model is suitable to predict the bending strength of beech glulam.

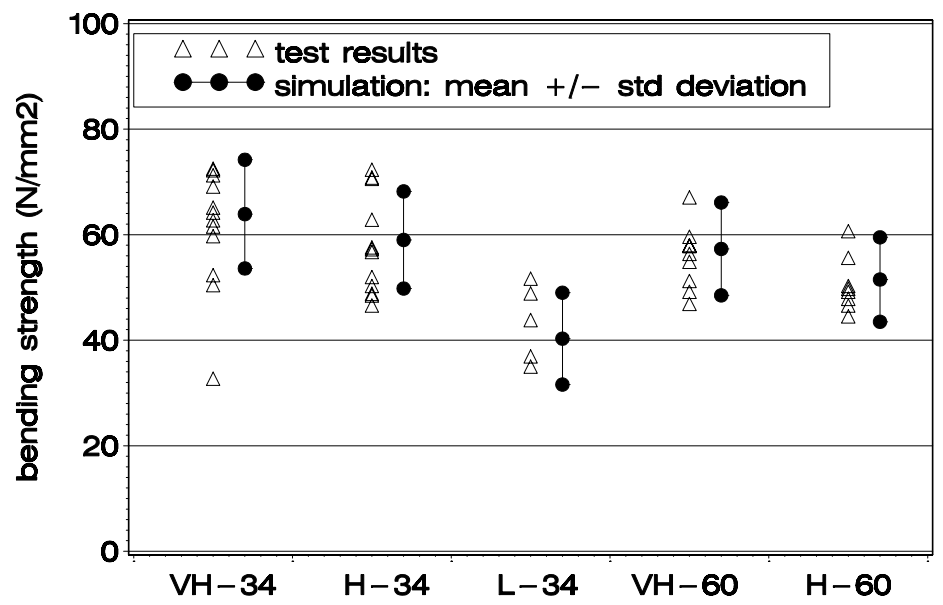

Fig. 15 Test results in comparison with simulation results

\section{Design proposals for beech glulam}

\subsection{Grading methods}

The design proposals were determined numerically. For that 7 grading methods as shown in Table 13 were developed having different influence on the tensile strength of the boards. The data of the 1888 boards were used to determine the appropriate density functions of the structural properties. These density functions were integrated into the calculation model to numerically reproduce the grading methods. The glulam bending strength was calculated for each of the models to study the influence of the boards tensile strength on the glulam bending strength. Thereby the characteristic tensile strength of the finger joints varied from $20 \mathrm{~N} / \mathrm{mm}^{2}$ to $60 \mathrm{~N} / \mathrm{mm}^{2}$ in steps of $5 \mathrm{~N} / \mathrm{mm}^{2}$. In this way 900 calculations were performed per step within a single grading method. The simulated beams have 20 laminations, a height of 600 $\mathrm{mm}$ and a span of $10,80 \mathrm{~m}$. The following $5^{\text {th }}$ percentile values were determined by the nonparametric method.

Table 13 Grading methods

\begin{tabular}{|c|c|c|}
\hline grade & knots & MOE $\left(\mathrm{N} / \mathrm{mm}^{2}\right)$ \\
\hline A & $0,33<\mathrm{DEB} \leq 0,80$ & - \\
B & $0,20<\mathrm{DEB} \leq 0,33$ & - \\
C & DEB $\leq 0,33$ & - \\
D & DEB $\leq 0,20$ & - \\
E & DEB $\leq 0,042$ & - \\
F & DEB $\leq 0,20$ & $15000<\mathrm{E}_{\text {dyn }}$ \\
G & DEB $\leq 0,042$ & $15000<\mathrm{E}_{\text {dyn }}$ \\
\hline
\end{tabular}




\subsection{Laminating effect}

\subsubsection{Laminating effect in terms of simulated strength values of $150 \mathrm{~mm}$ long sections}

The curves in Fig. 16 point out the relation between the characteristic glulam bending strength $\left(=f_{m, g, k}\right)$ and the variable characteristic tensile strength of finger joints $\left(=f_{t, j, k, s i m}\right)$. The maximum characteristic bending strength $\left(=\mathrm{f}_{\mathrm{m}, \mathrm{g}, \mathrm{k}, \mathrm{max}}\right)$ for each of the grades is clearly visible. The dashed line in Fig. 16 represents a linear relation between the glulam bending strength and the finger joint tensile strength, see equation (14). The gradient of this line is independent of the grading method or the tensile strength of boards, respectively, and applies until the trend becomes non-linear. The unit of strength values in the equations (14) - (21) is N/mm².

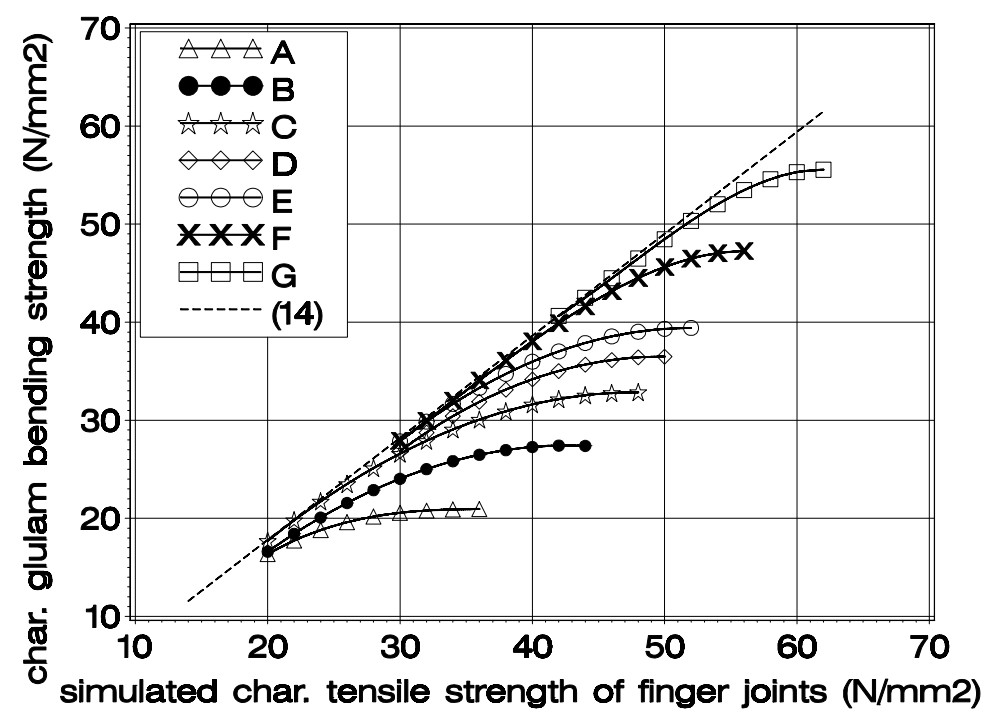

Fig. 16 Characteristic bending strength of glulam depending on simulated characteristic finger joint tensile strength

$$
f_{m, g, k}=-3+1,04 \cdot f_{t, j, k, s i m}
$$

The computation of the laminating effect in Table 14 shows the decrease of $\lambda$ with increasing characteristic tensile strength of the boards $\left(=\mathrm{f}_{\mathrm{t}, 1, \mathrm{k}, \mathrm{sim}}\right)$. Here, the characteristic tensile strength of the boards was determined using the calculation model. This is as expected and caused by the more homogeneous material properties in higher grades. Hence the laminating effect disappears as reported by Falk and Colling [7] for the case of softwood.

Table 14 Laminating effect $\lambda$

\begin{tabular}{|c|c|c|c|}
\hline grade & $\mathrm{f}_{\mathrm{t}, 1, \mathrm{k}, \mathrm{sim}}\left(\mathrm{N} / \mathrm{mm}^{2}\right)$ & $\mathrm{f}_{\mathrm{m}, \mathrm{g}, \mathrm{k}, \max }\left(\mathrm{N} / \mathrm{mm}^{2}\right)$ & $\lambda=\frac{\mathrm{f}_{\mathrm{m}, \mathrm{g}, \mathrm{k}, \mathrm{max}}}{\mathrm{f}_{\mathrm{t}, \mathrm{l}, \mathrm{k}, \mathrm{im}}}$ \\
\hline $\mathrm{A}$ & 17 & 21 & 1,24 \\
$\mathrm{~B}$ & 23 & 27,5 & 1,20 \\
$\mathrm{C}$ & 29 & 33 & 1,14 \\
$\mathrm{D}$ & 34 & 36,5 & 1,07 \\
$\mathrm{E}$ & 38 & 39,5 & 1,04 \\
$\mathrm{~F}$ & 46 & 47,3 & 1,03 \\
$\mathrm{G}$ & 54 & 55,5 & 1,03 \\
\hline
\end{tabular}


The simulation results as described in section 7 were merged into a single database and a multiple nonlinear regression analysis was performed to derive a general design proposal resulting in equation (15). It should be noted that the strength values of the independent variables refer to $150 \mathrm{~mm}$ long sections. The coefficient of correlation amounts to 0,99 .

$$
\mathrm{f}_{\mathrm{m}, \mathrm{g}, \mathrm{k}}=-2,09+0,913 \cdot \mathrm{f}_{\mathrm{t}, \mathrm{j}, \mathrm{k}, \mathrm{sim}}-0,0202 \cdot \mathrm{f}_{\mathrm{t}, \mathrm{j}, \mathrm{k}, \operatorname{sim}}{ }^{2}-0,0128 \cdot \mathrm{f}_{\mathrm{t}, \mathrm{l}, \mathrm{k}, \mathrm{sim}}{ }^{2}+0,0344 \cdot \mathrm{f}_{\mathrm{t}, \mathrm{j}, \mathrm{k}, \mathrm{sim}} \cdot \mathrm{f}_{\mathrm{t}, \mathrm{l}, \mathrm{k}, \operatorname{sim}}
$$

\subsubsection{Laminating effect in terms of strength values derived from standard test methods}

Equation (15) will be transformed with the intention to replace the independent variables with strength values derived from tests according to EN 408. First a relation between tensile strength and bending strength of finger joints has to be established. Blaß et al. [3] performed multiple tensile tests on $150 \mathrm{~mm}$ long finger joints and bending tests on finger joints according to EN 408. They proposed the relation in equation (16). Here, $\mathrm{f}_{\mathrm{m}, \mathrm{j}, \mathrm{k}}$ is the characteristic bending strength of finger joints. Colling et al. [8] proposed a quite similar factor of $1 / 0,7=1,43$ for softwood. Transforming the characteristic tensile strength of 150 $\mathrm{mm}$ board sections and the characteristic tensile strength of boards according to EN 408 $\left(=\mathrm{f}_{\mathrm{t}, \mathrm{l}, \mathrm{k}}\right)$, it is assumed that the test method affects more the measured strength values in case of lower lamination quality than in case of higher quality. A linear relation was derived as equation (17). The intercept and the gradient were determined fulfilling the following conditions: The relevant characteristic tensile strength according to EN 408 should amount to $70 \%(89 \%)$ of the characteristic tensile strength of $150 \mathrm{~mm}$ long board sections, if the latter value is $24 \mathrm{~N} / \mathrm{mm}^{2}\left(54 \mathrm{~N} / \mathrm{mm}^{2}\right)$. This coincides with values found by Colling and Falk [9], proposing a range from $71 \%$ up to $83 \%$, see also Falk and Colling [7].

Inserting equations (16) and (17) in equation (15) leads to the equation describing the characteristic bending strength of beech glulam in terms of strength values determined by standard test methods, see (18).

$$
\begin{aligned}
& \mathrm{f}_{\mathrm{m}, \mathrm{j}, \mathrm{k}} \approx 1,40 \cdot \mathrm{f}_{\mathrm{t}, \mathrm{j}, \mathrm{k}, \mathrm{sim}} \\
& \mathrm{f}_{\mathrm{t}, \mathrm{l}, \mathrm{k}} \approx-8,088+1,037 \cdot \mathrm{f}_{\mathrm{t}, \mathrm{l}, \mathrm{k}, \mathrm{sim}} \\
& \mathrm{f}_{\mathrm{m}, \mathrm{g}, \mathrm{k}}=-2,87+0,844 \cdot \mathrm{f}_{\mathrm{m}, \mathrm{j}, \mathrm{k}}-0,0103 \cdot \mathrm{f}_{\mathrm{m}, \mathrm{j}, \mathrm{k}}{ }^{2}-0,192 \cdot \mathrm{f}_{\mathrm{t}, 1, \mathrm{k}}-0,0119 \cdot \mathrm{f}_{\mathrm{t}, \mathrm{l}, \mathrm{k}}{ }^{2}+0,0237 \cdot \mathrm{f}_{\mathrm{m}, \mathrm{j}, \mathrm{k}} \cdot \mathrm{f}_{\mathrm{t}, \mathrm{l}, \mathrm{k}}
\end{aligned}
$$

The finger joint bending strength resulted in a characteristic value of $56 \mathrm{~N} / \mathrm{mm}^{2}$ in case of visual grading and $70 \mathrm{~N} / \mathrm{mm}^{2}$ in case of mechanical grading. Considering these values in equation (18), two design proposals can be derived for beech glulam made of visually graded boards, see equation (19), and mechanically graded boards, see equation (20). The beech glulam design proposals in comparison with the current model in EN 1194 referring to softwood, see equation (21), are shown in Fig. 17. There, the model according to equation (20) seems to be an adequate continuation of the model according to equation (21).

$$
\begin{aligned}
& \mathrm{f}_{\mathrm{m}, \mathrm{g}, \mathrm{k}}=12,0+1,13 \cdot \mathrm{f}_{\mathrm{t}, 1, \mathrm{k}}-0,0119 \cdot \mathrm{f}_{\mathrm{t}, 1, \mathrm{k}}^{2} \\
& \mathrm{f}_{\mathrm{m}, \mathrm{g}, \mathrm{k}}=5,66+1,47 \cdot \mathrm{f}_{\mathrm{t}, 1, \mathrm{k}}-0,0119 \cdot \mathrm{f}_{\mathrm{t}, 1, \mathrm{k}}^{2} \\
& \mathrm{f}_{\mathrm{m}, \mathrm{g}, \mathrm{k}}=7+1,15 \cdot \mathrm{f}_{\mathrm{t}, 1, \mathrm{k}}
\end{aligned}
$$




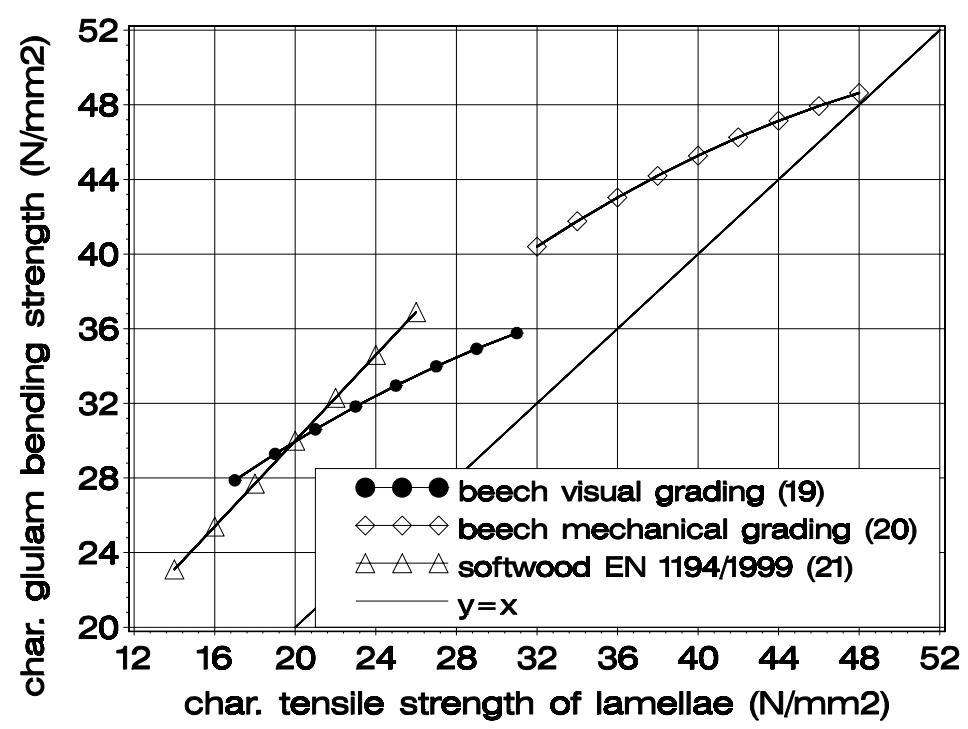

Fig. 17 Equations (19) and (20) in comparison with equation (21)

\section{Conclusions}

An extensive numerical and experimental investigation was carried out to determine the characteristic bending strength of beech glulam. Bending tests on full size beams composed of mechanically graded boards confirm a characteristic bending strength of at least $44,5 \mathrm{~N} / \mathrm{mm}^{2}$. A numerical approach was used to derive design proposals for beams with a height of 600 $\mathrm{mm}$. These proposals are valid for visual and mechanical grading of beech lamellae. Visual grading considering knots allows a characteristic bending strength up to $36 \mathrm{~N} / \mathrm{mm}^{2}$. Mechanical grading using the dynamic MOE from longitudinal vibration is a precondition to achieve characteristic bending strength values up to $48 \mathrm{~N} / \mathrm{mm}^{2}$.

\section{References}

[1] Görlacher R (1990). Klassifizierung von Brettschichtholzlamellen durch Messung von Longitudinalschwingungen - Grading of laminates by measuring longitudinal vibrations (only available in German). Karlsruhe, Universität (TH). Dissertation

[2] Glos P, Denzler JK, Linsenmann P (2004). Strength and Stiffness Behaviour of Beech Laminations for High Strength Glulam. CIB-W18/37-6-3. Edinburgh, Scotland

[3] Blaß HJ, Denzler JK, Frese M, Glos P, Linsenmann P (2004). Biegefestigkeit von Brettschichtholz aus Buche - Bending strength of beech glulam (only available in German). Band 1 der Reihe Karlsruher Berichte zum Ingenieurholzbau. Universitätsverlag Karlsruhe

[4] Ehlbeck J, Colling F, Görlacher R (1985). Einfluss keilgezinkter Lamellen auf die Biegefestigkeit von Brettschichtholzträgern - Influence of fingerjointed lamellae on the bending strength of glulam beams (only available in German). Holz als Roh- und Werkstoff. Vol. 43. P. 333-337, 369-373, 439-442

[5] Aicher S, Höfflin L, Behrens W, (2001). A study on tension strength of finger joints in beech wood laminations. Otto-Graf-Journal Vol.12

[6] Görlacher R (1984). Ein neues Messverfahren zur Bestimmung des Elastizitätsmoduls von Holz - A new method for determining the modulus of elasticity of timber (only available in German). Holz als Roh- und Werkstoff. Vol. 42. P. 219-222 
[7] Falk RH, Colling F (1995). Laminating Effects in Glued-Laminated Timber Beams. Journal of Structural Engineering. December 1995. P. 1857-1863

[8] Colling F, Ehlbeck J, Görlacher R (1991). Glued Laminated Timber - Contribution to the Determination of the Bending Strength of Glulam Beams. CIB-W18A/24-12-1. Oxford, United Kingdom

[9] Colling F, Falk RH (1993). Investigation of Laminating Effects in Glued-Laminated Timber. CIB-W18/26-12-1. Athens, Georgia, USA

EN 408, Ausgabe April 1996. Bauholz für tragende Zwecke und Brettschichtholz Bestimmung einiger physikalischer und mechanischer Eigenschaften - Structural timber and glued laminated timber - Determination of some physical and mechanical properties

EN 1194, Ausgabe April 1999. Brettschichtholz - Festigkeitsklassen und Bestimmung charakteristischer Werte - Glued laminated timber - Strength classes and determination of characteristic values

DIN 4074, Ausgabe Juni 2003. Sortierung von Holz nach der Tragfähigkeit, Teil 5: Laubschnittholz - Strength grading of wood - Part 5: Sawn hard wood (only available in German) 